\title{
Evaluation of the effect of vertebral and disc mechanical torsion on the correction achieved by posterior instrumentation in adolescent idiopathic scoliosis
}

\author{
Daniel Birchall*, David Hughes and Brad Williamson
}

Address: Consultant and Head of Division, Northern Neurosciences Centre, Newcastle, UK

Email: Daniel Birchall* - Daniel.Birchall@nuth.nhs.uk

* Corresponding author

\author{
from 4th International Conference on Conservative Management of Spinal Deformities \\ Boston, MA, USA. 13-16 May 2007 \\ Published: 12 October 2007 \\ Scoliosis 2007, 2(Supp| I):S28 doi:I0.I|86/I748-7|6I-2-SI-S28
}

This abstract is available from: http://www.scoliosisjournal.com/content/2/SI/S28

(C) 2007 Birchall et al; licensee BioMed Central Ltd.

\section{Objectives}

To evaluate the effect of rotational deformation ('mechanical torsion') on the short-term and long-term effectiveness of modern posterior spinal instrumentation in treating the three-dimensional deformity of adolescent idiopathic scoliosis.

\section{Methods}

Ten patients with idiopathic scoliosis were imaged with three-dimensional magnetic resonance imaging pre-operatively and at six weeks and twelve months post-operatively following Isola posterior instrumentation [1]. Changes in the three-dimensional deformity were measured, and the effect of mechanical torsion within the vertebral bodies and discs on the overall changes analysed.

\section{Results}

Posterior instrumentation causes partial and temporary improvement in disc mechanical torsion but insignificant improvement in vertebral mechanical torsion. Changes in disc torsional deformity correlate with changes in apical rotation, Cobb angle and thoracic hypokyphosis.

\section{Conclusion}

Mechanical torsion within the vertebral bodies and discs of patients with idiopathic scoliosis presents a fundamental obstacle to effective derotational surgery, and is closely related to subsequent changes in the overall three-dimensional deformity following instrumentation.

\section{References}

I. Benli IT, Akalin S, Aydin E, Baz A, Citak M, Kis M, Duman E: Isola spinal instrumentation system for IS. Arch Orthop and Trauma Surgery 200I, I 2 I: I7-25. 